\title{
Research Methods and Applications of Gear Manufacturing Process Optimization
}

\author{
Qiang Li, ${ }^{1,2}$ Liyang Xie $\mathbb{C D}^{1,2}$ Jiaxin Song, ${ }^{1,2}$ Haiyang Li, ${ }^{1,2}$ and Guoliang Xu ${ }^{3}$ \\ ${ }^{1}$ School of Mechanical Engineering and Automation, Northeastern University, Shenyang 110819, China \\ ${ }^{2}$ Key Laboratory of Vibration and Control of Aero-Propulsion System Ministry of Education, Northeastern University, \\ Shenyang, Liaoning 110819, China \\ ${ }^{3} 702$ Institute of China Aerospace Science and Technology Group, Beijing 100076, China
}

Correspondence should be addressed to Liyang Xie; lyxieneu@163.com

Received 22 January 2019; Revised 16 April 2019; Accepted 16 May 2019; Published 28 May 2019

Academic Editor: A. M. Bastos Pereira

Copyright (C) 2019 Qiang Li et al. This is an open access article distributed under the Creative Commons Attribution License, which permits unrestricted use, distribution, and reproduction in any medium, provided the original work is properly cited.

This paper presents an optimization method for gear processes; through this method, the most worth optimized processes can be obtained and optimized, thus improving the reliability and supportability of gear products. Firstly, the POPN (Process Optimization Priority Number) analysis method considering the current process level and the process improvement cost is proposed with reference to the RPN (Risk Priority Number) analysis method to obtain the most worth optimized processes. Due to the fact that the unreasonable weight distribution of importance (I), changing difficulty (C), rationality (R), and detective difficulty (D) still exists in the POPN analysis, then combining the POPN analysis method and the AHP (Analytic Hierarchy Process)-fuzzy comprehensive evaluation method to evaluate and rank the FPOPN (fuzzy POPN) level of each process, the higher the FPOPN level is, the more the process should be optimized. Finally, according to the evaluation results, some processes with high FPOPN level are optimized and the optimal parameters' combination of these processes is obtained through the tests based on the Taguchi method. A detailed optimization example is also given from the beginning to end in accordance with the above methods, and compared with the original process gears, the optimized gears have a big increase in gear performance through the above optimization method.

\section{Introduction}

Gear transmission is the most important and widely used transmission in mechanical transmission, and the gear performance directly affects the performance of the entire transmission system. In particular, long-life precision gears are widely used in mechanical transmission systems with high reliability requirements, such as wind turbine gearboxes [1] and aero engines. With the continuous advancement of science and technology, the requirements for long-life precision gears are also increasing. There are many manufacturing processes that affect the performance of gears, but so far, few researchers have performed a complete optimization analysis for them. Therefore, in this paper, a method is proposed with reference to the RPN (Risk Priority Number) analysis method in the FMECA (Failure Mode and Effect Criticality Analysis) to obtain the most worth optimized processes.
FMEA (Failure Mode and Effects Analysis) is a systematic procedure for the analysis of a system/process to identify the potential failure modes, causes, and effects on the system performance [2]. When FMEA is used in prioritization of failure modes, it is referred to as failure mode effect criticality analysis (FMECA) [3].

Traditional CA (Criticality Analysis) of FMECA is the $\mathrm{RPN}$ analysis. RPN is to multiply the Severity, Occurrence rate, and Detection of a certain failure mode of the product [4]:

$$
\begin{gathered}
R P N=\text { Severity }(S) * \text { Occurrence }(O) \\
* \text { Detection }(D)
\end{gathered}
$$

Each risk factor generally takes a discrete value in the range $[0,10]$.

The FMECA analysis is widely used in different fields, M. Catelani et al. combined FMECA and FMMEA (Failure 
Modes, Mechanisms and Effect Analysis) to perform failure analysis in a redundant architecture based on temperature sensors included in a Safety Instrumented System for Oil \& Gas application [5]. Hu-Chen Liu et al. reviewed 75 FMEA papers published between 1992 and 2012 in the international journals and categorized them according to the approaches used to overcome the limitations of the conventional RPN method and, then gave a review on the risk evaluation approaches in FMECA [6]. Therefore, it is meaningful to propose an effective analysis method for optimization priority analysis of gear processes by referring to the RPN analysis method in FMECA.

Although RPN analysis is widely used in different fields, many researchers have pointed out the following shortcomings $[6,7]$.

(1) The relative importance among $\mathrm{O}, \mathrm{S}$, and $\mathrm{D}$ is not taken into consideration; the RPN cannot assign the weights of S, O, D, and only performs simple multiplication. For different systems and components, these three risk factors contribute differently to failure modes.

(2) The RPN is not a continuous function so that the meaning of the differences among the RPN values causes some interpretation problems.

(3) Different combinations of O, S, and D may produce exactly the same value of RPN, but their hidden risk implications may be totally different.

(4) The three risk factors are difficult to be precisely evaluated.

(5) The RPN considers only three risk factors mainly in terms of safety, which is not appropriate for all engineering fields.

For the above shortcomings of RPN, the multicriteria decisional approach allows the Decision Maker at taking into account, contrarily to the traditional approach based on the RPN computation, the relative importance of risk parameters as well as his/her uncertainty in assigning each failure mode to a specific risk class [8]. Braglia, $M$ et al. presented a decision-making support system for failure mode and effect and criticality analysis in production systems based on the fuzzy logic technique and the analytical hierarchy process (AHP) [9]. Zammori F et al. presented a more comprehensive risk assessment procedure called Analytic Network Process (ANP)/RPN, which combines FMECA and ANP, and the ANP is a multicriteria decision-making approach that provides a framework to cope with decision situations involving qualitative and quantitative aspects [10]. In addition, the multicriteria decisional approach for prioritizing failures in FMECA has been widely used in domestic appliance [11] and marine machinery systems [12]. However, in this paper, the combination of AHP and fuzzy logic is used to solve the shortcomings of RPN.

For the relative importance among $\mathrm{O}, \mathrm{S}$, and D which is not taken into consideration, Kyungmee O. Kim et al. presented a general model to explain the functional relationship among the three factors, especially the interrelationships among them [13]. However, in this paper, we use the AHP to assign weights for the influence factors. The AHP was first established by Saaty to aid in decision-making for problems that involves multiple criteria [14], and the AHP has been used extensively by researchers in many applications. Jian Guo et al. used the fuzzy analytic hierarchy process (AHP) to determine the subjective weight vector of the risk factors for failure modes and effects analysis of $\mathrm{CO} 2$ transmission pipelines [15]. Reza Fattahi et al. used the fuzzy AHP method to calculate the weights of time, cost, and profit in fuzzy weighted risk priority number (FWRPN) [16].

For the second to fourth shortcomings of RPN, fuzzy logic can be used for estimating the risk when there are uncertainties in parameters involved in risk calculation, and fuzzy logic does not define sharp boundaries in the classification of these parameters. The fuzzy comprehensive evaluation method has been extensively used in various industries. Dejan V. Petrovic et al. proposed a risk assessment model for mining equipment system based on the fuzzy sets theory, fuzzy logic, and minmax composition and proved the rationality of the model by comparing the traditional RPN analysis [17]. In view of the uncertainty of seaport operational risk data, Andrew John et al. divided the risk factors of seaport operation into five categories, operational risk, security risk, technical risk, organizational risk, and natural risk, and evaluated each risk factor based on APH-fuzzy comprehensive evaluation method [18]. Nalinee Chanamool et al. combined the fuzzy set theory with FMEA to conduct a risk evaluation of the hospital's emergency department and verified the effectiveness of the fuzzy FMEA method by improving the highrisk factors [19]. Yasal Ozdemir et al. proposed an approach which incorporates 5S methodology, FMEA, interval typetwo fuzzy sets, AHP, and the VlseKriterijumska Optimizacija I Kompromisno Resenje to assess the occupational hazards and associated risks [20]. In addition, fuzzy comprehensive evaluation is widely used in mechanical devices [21], wind power systems [22], agriculture [23], and other fields, but few researchers have carried out fuzzy comprehensive evaluation on the optimization priority analysis of each process of a product manufacturing process.

For the last shortcoming of RPN analysis method, the POPN (Process Optimization Priority Number) analysis method is proposed, which takes into account the factors that enterprises attach great importance to, such as the process improvement cost and current process rationality. Then combining the POPN analysis method and the AHPfuzzy comprehensive evaluation method, the FPOPN (fuzzy POPN) level of each process of the gear production process can be evaluated and ranked, the higher the FPOPN level is, the more the process should be optimized.

After the evaluation, it is necessary to optimize the processes with high FPOPN level. The Taguchi method can be used to optimize the processes and get the optimal parameters' combination of the processes through tests. The Taguchi method has been widely used for design and analyze of various engineering fields such as chemical industry [24], carbon nanotube [25], soil [26], and energy [27], and it is demonstrated to be a powerful tool due to its simplicity and robustness [28]. Through the Taguchi method, we can 


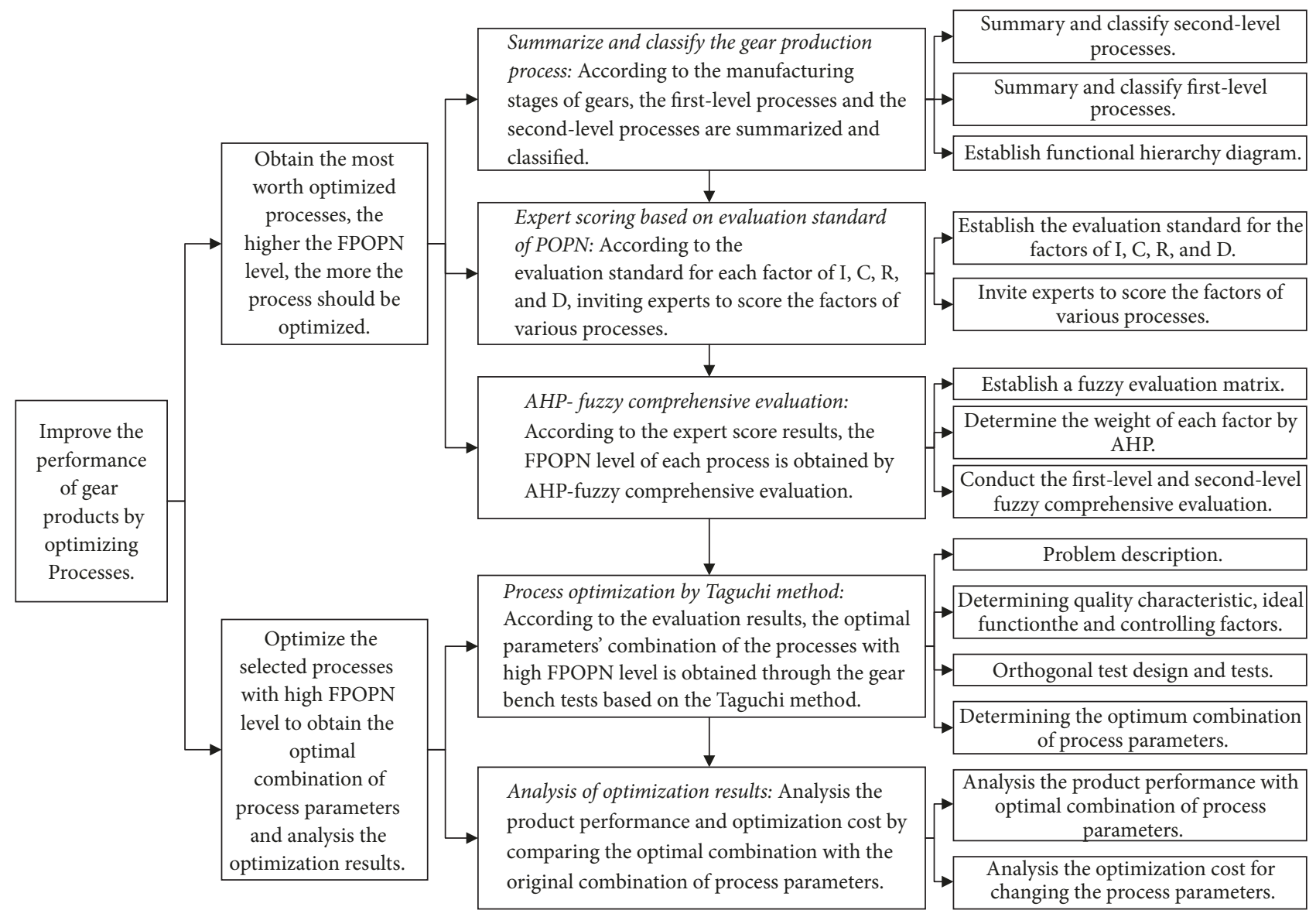

FIGURE 1: The general steps of gear process optimization.

also analyze the product performance and optimization cost by comparing the optimal combination with the original combination of process parameters.

In summary, we can develop a specific method for gear process optimization, as shown in the Figure 1. As can be seen from the Figure 1, the ultimate objective of this method is to improve gear performance, and the ultimate objective can be divided into two main objectives, one is to obtain the most worth optimized processes by the combination of POPN method and AHP-fuzzy comprehensive evaluation method, and the other is to optimize the selected processes with high FPOPN level by the Taguchi method. A detailed optimization example is also given from the beginning to end according to the steps in this paper.

\section{Gear Production Process}

The production process of 20CrMnTi gear produced by a gear manufacturer is taken as the research and analysis object. Due to the harsh service conditions and high technical requirements of long-life precision gears, the carburizing grinding process is used for gear manufacturing. Using the brainstorming method, the gear manufacturing personnel, especially the process operators, are called together to discuss which processes have an important influence on the gear quality. As shown in Figure 1, the gear production process is divided into seven stages according to the production sequence, which are the structural dimension design stage, material selection stage, forging stage, roughing stage, heat treatment stage, finish machining stage, and testing stage, each stage is composed of different second-level processes, and the lowest conventional layer is the first-level processes which belong to the second-level processes.

Since there are 20 second-level processes and 88 firstlevel processes involved in the entire production process, it cannot be fully displayed in Figure 2. Therefore, only the second-level processes and first-level processes of the fifth manufacturing stage (heat treatment stage) are shown in Figure 2. Figure 3 is a functional hierarchy diagram of the corresponding processes.

\section{The POPN Analysis}

3.1. The Presentation of POPN Analysis. In this paper, the POPN analysis method with reference to the RPN is proposed to analyze the gear processes. The POPN analysis method takes into account the current process level and the cost of the process improvement which enterprises attach great importance to. The analysis data is obtained by multiplying the importance of the process (I), the changing difficulty 


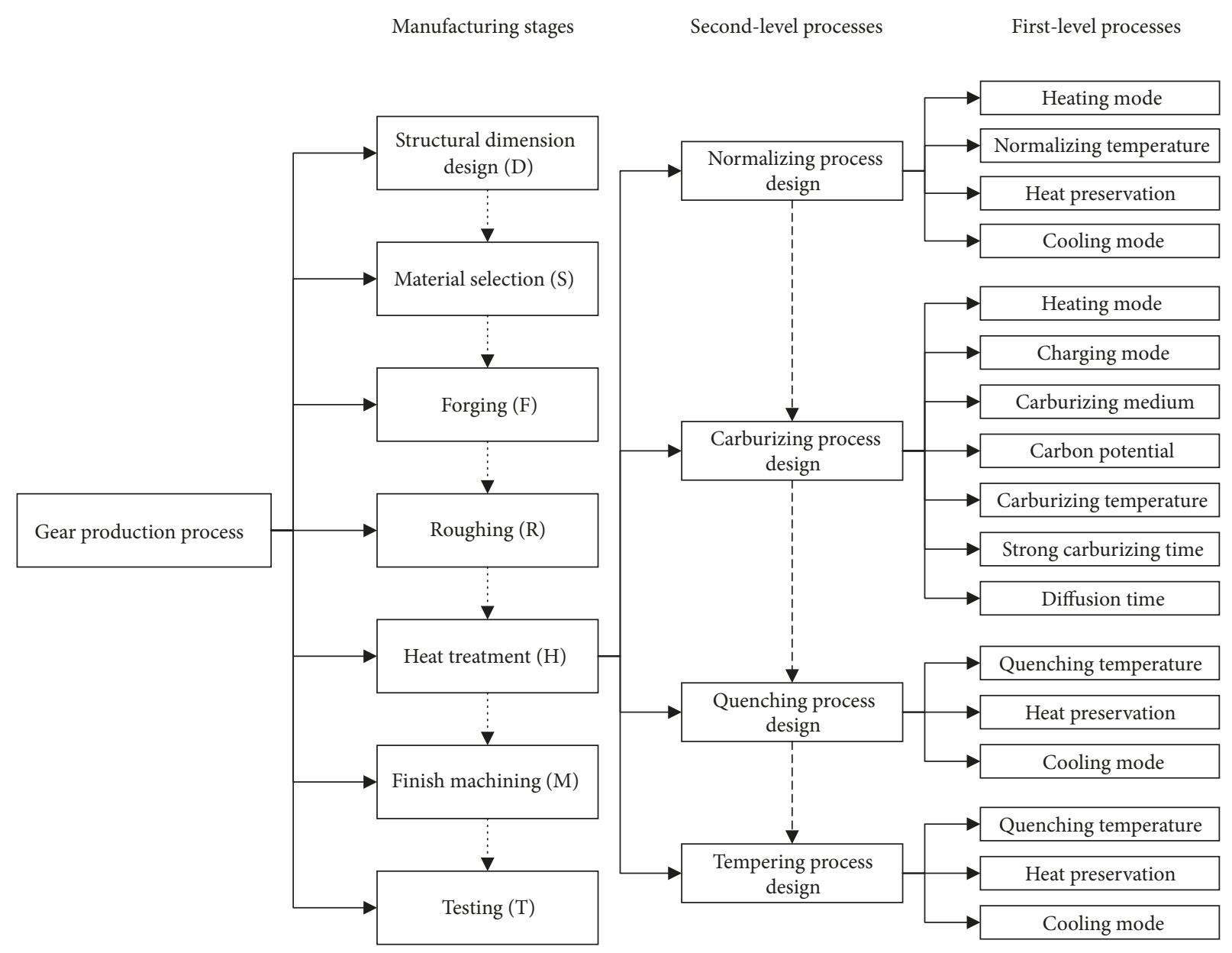

Figure 2: Gear production process.

of the process parameter (considering time-consuming and cost) (C), the rationality of the current process parameter (comparing advanced level) (R), and the detection difficulty of the irrational process parameter (D), as shown in (2).

$$
P O P N=I \times C \times R \times D
$$

POPN reflects a comprehensive measure of optimization and improvement of the process. The larger the POPN value is, the more preferential the process should be optimized.

3.2. The Evaluation Standards for Factors. The evaluation standard for each factor of I, C, R, and D is shown in Table 1. Here, the evaluation value of each factor is divided into five levels for the evaluators to refer to, so as to accurately score the factors of processes, thereby obtaining the POPN value.

The evaluation process has been completed by 10 experts' on-site investigation, which makes the results of the scoring more credible. The selection of evaluation experts is composed of scholars, researchers, and technicians who have rich practical experience in the research and development of longlife precision gear manufacturing.

As for the importance of process, the influence degree on fatigue properties of gears is taken as the evaluation criterion. After consultation by the expert group, it is considered that when a certain process parameter is unreasonable, the gear fatigue limit is reduced within $5 \%$, then the importance degree of the process is considered to be very low, and the other importance degree evaluation contents are shown in Table 1. For example, when the strong carburizing time is insufficient in the carburizing process, resulting in insufficient depth of the carburizing layer, most experts believe that the influence degree of insufficient depth of carburizing layer on the fatigue property is usually between $20 \%$ and $30 \%$, so the importance score is 7-8. In contrast, for the number of gear web holes, experts agree that the influence degree of the fatigue property is less than $5 \%$, so the importance score is 1-2.

As for the changing difficulty of process parameters, the evaluation criteria are the manpower, material resources, and time invested in changing the process parameters. When changing the process parameters, the cost of replacing or improving the equipment is more than 3 million CNY or more than one year's research and development time, a large amount of manpower, material resources, and time are required, it is considered that the difficulty of changing is very high, and the other evaluation contents of changing difficulty are shown in Table 1. For example, when the precision of grinding process is improved by replacing better grinding machine tools, especially replacing imported 


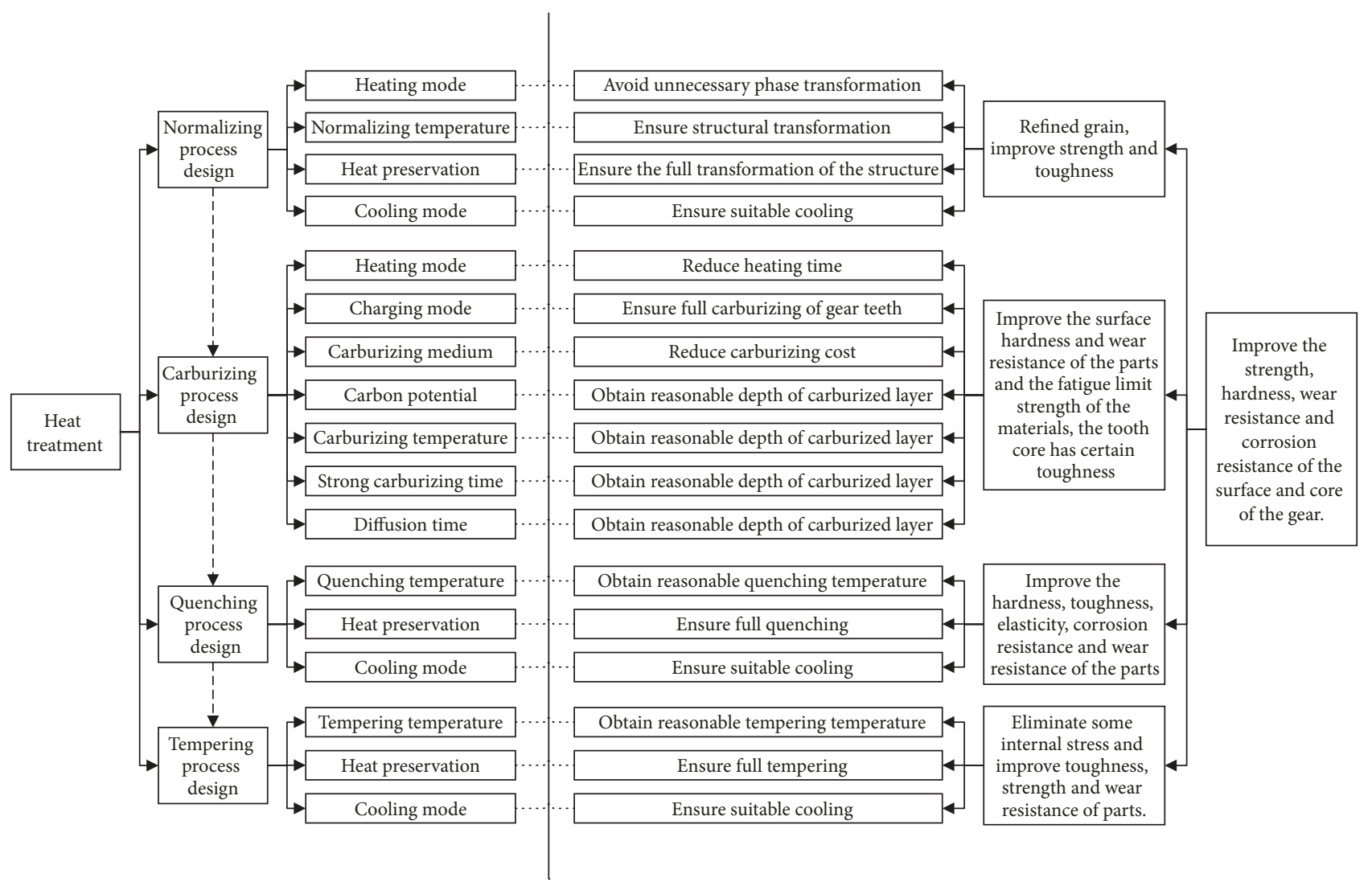

FIgURE 3: Functional hierarchy diagram.

equipment, it will cost about 5 million CNY, and it will take more than half a year after approval, placing an order, transportation, and installation, so the score of changing difficulty is 1-2. In contrast, it is relatively easy to change the grinding wheel type or grinding wheel speed, so the score of changing difficulty is 7-10.

As for the rationality of the current process parameters, one depends on the expert's knowledge of the current process, and the other is the comparison with other competitors and even the international advanced level. For example, for the axial width of the gear hub, compared with the gears of other factories, it is found that the current hub width is relatively small, which affects the stability of the gear transmission, so the reasonableness score is 7- 8 points.

As for the detection difficulty of irrational process parameters, the difficulty of detecting the irrational process parameters is the main criterion. For example, whether the chemical composition of gear material is reasonable needs to be tested (score 5-6), normalizing temperature can be checked and controlled at any time (score 1-2), and gear modification needs simulation and even gear bench test to find out if it is reasonable (score 7-8).

\section{AHP-Fuzzy Comprehensive Evaluation of the Gear Manufacturing Processes}

Although POPN analysis method is more suitable for process optimization analysis, it still has some shortcomings similar to RPN analysis method, which has been explained in the introduction. According to the expert score results, fuzzy logic can be used for estimating the POPN when there are uncertainties in parameters involved in POPN calculation, and the AHP can be used to determine the weight distribution of each factor in POPN, so it is necessary to combine APHfuzzy comprehensive evaluation method and POPN analysis method to obtain the FPOPN level of each process. The AHPfuzzy comprehensive evaluation process is usually divided into six steps, as shown in Figure 4. In order to better demonstrate the calculation process of the method, taking one first-level process as a research object to illustrate by examples.

4.1. Establish a Fuzzy Evaluation Matrix. Before establishing the fuzzy evaluation matrix, it is necessary to establish a factor set and a factor evaluation set. The factor set is a set of factors affecting the evaluation objects, and different elements represent different factors. It is represented by the set $U$, that is,

$$
U=\left\{u_{1}, u_{2}, u_{3}, u_{4}\right\}
$$

$u_{1}, u_{2}, u_{3}, u_{4}$ represent the importance of the process (I), the changing difficulty (considering time-consuming and cost) (C), the rationality of current process parameter (R), and the detection difficulty of irrational process parameter (D). 
TABLE 1: The evaluation standard for the factors.

\begin{tabular}{|c|c|c|c|}
\hline Factors & Degree & evaluation contents & Score \\
\hline \multirow{5}{*}{ Importance (I) } & Very low & The influence on gear fatigue property $\leqslant 5 \%$ & $1-2$ \\
\hline & Low & $\begin{array}{c}5 \%<\text { The influence on gear fatigue } \\
\text { property } \leqslant 10 \%\end{array}$ & $3-4$ \\
\hline & Medium & $\begin{array}{c}10 \%<\text { The influence on gear fatigue } \\
\text { property } \leqslant 20 \%\end{array}$ & $5-6$ \\
\hline & High & $\begin{array}{c}20 \%<\text { The influence on gear fatigue } \\
\text { property } \leqslant 30 \%\end{array}$ & $7-8$ \\
\hline & Very high & The influence on gear fatigue property $>30 \%$ & $9-10$ \\
\hline \multirow{5}{*}{$\begin{array}{l}\text { Changing } \\
\text { difficulty }(C)\end{array}$} & Very high & $\begin{array}{l}\text { It takes more than } 3 \text { million CNY for } \\
\text { equipment to be replaced or improved, or more } \\
\text { than one year for research and development. }\end{array}$ & $1-2$ \\
\hline & High & $\begin{array}{l}\text { It takes more than } 1 \text { million CNY for } \\
\text { equipment to be replaced or improved, or more } \\
\text { than half a year for research and development. }\end{array}$ & $3-4$ \\
\hline & Medium & $\begin{array}{l}\text { It takes more than } 0.5 \text { million CNY for } \\
\text { equipment to be replaced or improved, or more } \\
\text { than } 3 \text { months for research and development. }\end{array}$ & $5-6$ \\
\hline & Low & $\begin{array}{l}\text { It takes more than } 0.1 \text { million CNY for } \\
\text { equipment to be replaced or improved, or more } \\
\text { than one month for research and development. }\end{array}$ & $7-8$ \\
\hline & Very low & $\begin{array}{l}\text { It takes less than } 0.1 \text { million CNY for } \\
\text { equipment to be replaced or improved, or less } \\
\text { than one month for research and development. }\end{array}$ & $9-10$ \\
\hline \multirow{5}{*}{ Rationality (R) } & Very high & $\begin{array}{l}\text { The current process parameter has reached the } \\
\text { best value and should be maintained. }\end{array}$ & $1-2$ \\
\hline & High & $\begin{array}{l}\text { The current process parameter is close to the } \\
\text { best value and doesn't need to be changed. }\end{array}$ & $3-4$ \\
\hline & Medium & $\begin{array}{l}\text { The current process parameter has a slight gap } \\
\text { with the best value and should be slightly } \\
\text { improved. }\end{array}$ & $5-6$ \\
\hline & Low & $\begin{array}{c}\text { The current process parameter has a big gap } \\
\text { with the best value and should be studied and } \\
\text { improved. }\end{array}$ & $7-8$ \\
\hline & Very low & $\begin{array}{c}\text { The current process parameter deviates } \\
\text { completely from the best value and need urgent } \\
\text { improvement. }\end{array}$ & $9-10$ \\
\hline \multirow{5}{*}{$\begin{array}{l}\text { Detection } \\
\text { difficulty (D) }\end{array}$} & Very low & Only need simple observation. & $1-2$ \\
\hline & Low & Some testing tools are needed. & $3-4$ \\
\hline & Medium & Need some simple tests. & $5-6$ \\
\hline & High & Need a lot of tests. & $7-8$ \\
\hline & Very high & Need to be found in use. & $9-10$ \\
\hline
\end{tabular}

Then establishing a factor evaluation set, it is represented by the set $V$; each factor is divided into five levels, namely,

$$
V=\left\{v_{1}, v_{2}, v_{3}, v_{4}, v_{5}\right\}
$$

The criteria for the evaluation refer to Table 1.

If there are $h_{i j}$ individuals in the $h$ expert members who evaluate the $i$ th factor $u_{i}$ to belong to the factor evaluation level $v_{j}$, then the fuzzy evaluation set of $u_{i}$ is

$$
R_{i}=\left\{\frac{h_{i 1}}{h}, \frac{h_{i 2}}{h}, \ldots, \frac{h_{i 5}}{h}\right\}=\left\{r_{i 1}, r_{i 2}, \ldots, r_{i 5}\right\}
$$

$$
\sum_{j=1}^{5} \frac{h_{i j}}{h}=1
$$

According to the fuzzy evaluation set of each factor, the fuzzy evaluation matrix $R$ can be obtained:

$$
R=\left[R_{1}, R_{2}, R_{3}, R_{4}\right]^{T}=\left[\begin{array}{cccc}
r_{11} & r_{12} & \ldots & r_{15} \\
r_{21} & r_{22} & \ldots & r_{25} \\
r_{31} & r_{32} & \ldots & r_{35} \\
r_{41} & r_{42} & \ldots & r_{45}
\end{array}\right]
$$


TABLE 2: Nine-quantile scaling.

\begin{tabular}{|c|c|c|c|c|c|c|c|c|c|}
\hline $\begin{array}{l}\text { A index } \\
\text { relative to B } \\
\text { index }\end{array}$ & $\begin{array}{l}\text { Extremely } \\
\text { important }\end{array}$ & $\begin{array}{c}\text { Very } \\
\text { important }\end{array}$ & Important & $\begin{array}{l}\text { Slightly } \\
\text { important }\end{array}$ & $\begin{array}{c}\text { Equally } \\
\text { important }\end{array}$ & $\begin{array}{c}\text { Slightly } \\
\text { secondary }\end{array}$ & Secondary & $\begin{array}{c}\text { Very } \\
\text { secondary }\end{array}$ & $\begin{array}{l}\text { Extremely } \\
\text { secondary }\end{array}$ \\
\hline $\begin{array}{l}\text { A index } \\
\text { evaluation } \\
\text { value }\end{array}$ & 9 & 7 & 5 & 3 & 1 & $1 / 3$ & $1 / 5$ & $1 / 7$ & $1 / 9$ \\
\hline Remarks & & Take $8,6,4$ & $1 / 2,1 / 4,1 / 6$ & 8 as the int & mediate val & of the abo & evaluation $\mathrm{v}$ & & \\
\hline
\end{tabular}

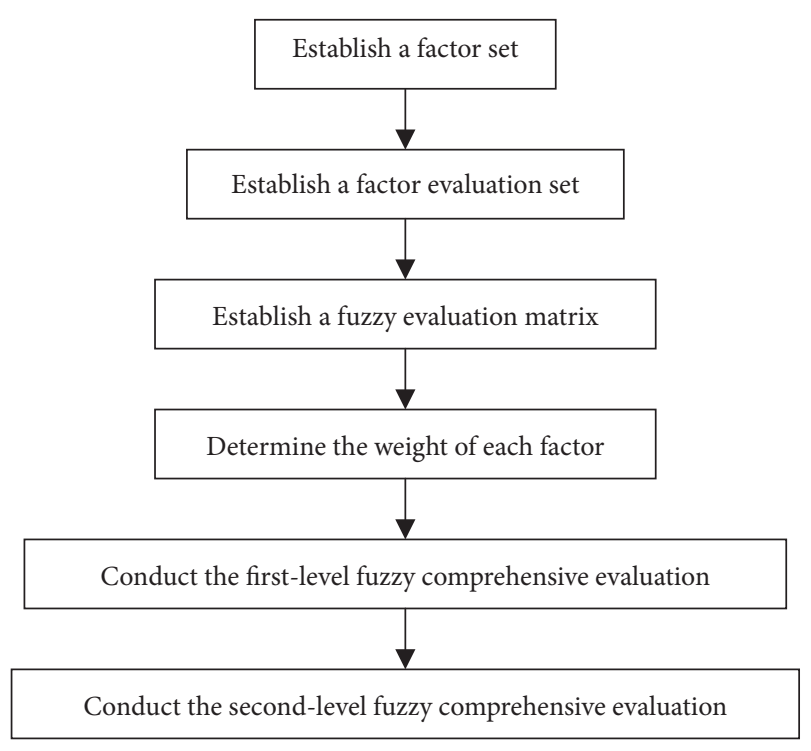

FIGURE 4: The AHP-fuzzy comprehensive evaluation process.

Taking the strong carburizing time of carburizing process design in heat treatment stage as the research object, the fuzzy evaluation matrix of the process is established as an illustration.

Through the on-site investigation of 10 experts, the evaluation set of $\mathrm{I}$ is $R_{1}=\{0,0,0.2,0.6,0.2\}$, the evaluation set of $\mathrm{C}$ is $R_{2}=\{0,0,0.1,0.6,0.3\}$, the evaluation set of $\mathrm{R}$ is $R_{3}=\{0,0.1,0.2,0.4,0.3\}$, and the evaluation set of $\mathrm{D}$ is $R_{4}=\{0,0,0.2,0.7,0.1\}$, namely,

$$
R_{5}^{10}=\left[\begin{array}{ccccc}
0 & 0 & 0.2 & 0.6 & 0.2 \\
0 & 0 & 0.1 & 0.6 & 0.3 \\
0 & 0.1 & 0.2 & 0.4 & 0.3 \\
0 & 0 & 0.2 & 0.7 & 0.1
\end{array}\right]
$$

In the equation, $R_{5}^{10}$ represents the 10th first-level process (strong carburizing time) of the fifth stage (heat treatment stage) of the gear production process.

4.2. Determine the Weight of Each Factor. Since the contribution of each factor in the POPN analysis should be different, set a factor weight vector $\mathrm{W}$ :

$$
W=\left[a_{1}, a_{2}, a_{3}, a_{4}\right]
$$

TABLE 3: The matrix table of nine-quantile scaling.

\begin{tabular}{ccccc}
\hline$u_{i}$ & $u_{1}$ & $u_{2}$ & $u_{3}$ & $u_{4}$ \\
\hline$u_{1}$ & 1 & $1 / 3$ & $1 / 4$ & 1 \\
$u_{2}$ & 3 & 1 & $1 / 2$ & 3 \\
$u_{3}$ & 4 & 2 & 1 & 4 \\
$u_{4}$ & 1 & $1 / 3$ & $1 / 4$ & 1 \\
\hline
\end{tabular}

$$
\sum_{i=1}^{4} a_{i}=1
$$

$a_{1}, a_{2}, a_{3}, a_{4}$ present the weight of I, C, R, and D.

The AHP was first established by Saaty to aid in decisionmaking for problems that involves multiple criteria [24]; AHP is used to determine the weight distribution of each factor in this paper. Firstly, ten experts evaluate the relative importance of the four factors through the nine-quantile scaling (Table 2). Then, the evaluation results are filled into the nine-quantile scaling matrix table to obtain the weight evaluation matrix. Table 3 shows the nine-quantile scaling matrix table completed by the first expert. Each element in the matrix table represents the importance of the $i$ th row factor relative to the $j$ th column factor.

The maximum eigenvalue, eigenvector $A$, and consistency check value of the weight evaluation matrix are calculated by referring to the literature $[14,29]$. According to the calculation results, the maximum eigenvalue $\lambda_{\max }=$ 4.0205 , and the corresponding eigenvector is normalized as $A=[0.1094,0.2967,0.4845,0.1094]$, and the consistency test result $C R=0.0077<0.1$. Therefore, the first evaluation matrix satisfies the consistency requirement, so the weight distribution of the first expert for each factor is $0.1094,0.2967$, 0.4845 , and 0.1094 .

According to the above method, the same weight calculation method is adopted for the remaining nine weight evaluation matrices in Table 4, and the weight of each factor is averaged arithmetically in Table 5. Finally, $W=$ $[0.1486,0.3029,0.4438,0.1047]$ was obtained.

4.3. Conduct the First-Level and Second-Level Fuzzy Comprehensive Evaluation. The strong carburizing time of the first-level processes is still the calculation object. The firstlevel fuzzy comprehensive evaluation vector is obtained by multiplying the weight vector with the fuzzy evaluation matrix, namely, 
TABLE 4: The remaining nine weight evaluation matrices.

$\left.\begin{array}{lccc}1 & 1 / 2 & 1 / 3 & 2 \\ 2 & 1 & 1 / 2 & 3 \\ 3 & 2 & 1 & 5 \\ 1 / 2 & 1 / 3 & 1 / 5 & 1\end{array}\right]$
$\left[\begin{array}{ccccccccc}1 & 1 / 2 & 1 / 4 & 2 \\ 2 & 1 & 1 / 2 & 3 \\ 4 & 2 & 1 & 4 \\ 1 / 2 & 1 / 3 & 1 / 4 & 1\end{array}\right]$
$\left[\begin{array}{cccc}1 & 1 / 2 & 1 / 3 & 1 \\ 2 & 1 & 1 / 2 & 2 \\ 3 & 2 & 1 & 3 \\ 1 & 1 / 2 & 1 / 3 & 1\end{array}\right]$

TABLE 5: The weight distributions of ten experts.

\begin{tabular}{lcccc}
\hline & $a_{1}$ & $a_{2}$ & $a_{3}$ & $a_{4}$ \\
\hline Expert 1 & 0.1094 & 0.2967 & 0.4845 & 0.1094 \\
Expert 2 & 0.1569 & 0.2717 & 0.4832 & 0.3512 \\
Expert 3 & 0.1887 & 0.3512 & 0.4704 & 0.10892 \\
Expert 4 & 0.1358 & 0.2797 & 0.4901 & 0.1141 \\
Expert 5 & 0.1457 & 0.2711 & 0.5318 & 0.0931 \\
Expert 6 & 0.1855 & 0.1855 & 0.2776 & 0.0972 \\
Expert 7 & 0.1602 & 0.4669 & 0.4551 & 0.1411 \\
Expert 8 & 0.1411 & 0.2627 & 0.3937 & 0.0753 \\
Expert 9 & 0.1373 & 0.3937 & 0.5000 & 0.1250 \\
Expert 10 & 0.1250 & 0.2500 & 0.4438 & 0.1047 \\
The average values & 0.1486 & 0.3029 & & \\
\hline
\end{tabular}

$$
\begin{aligned}
B_{5}^{10} & =W \cdot R_{5}^{10} \\
& =[0.0000,0.0444,0.1697,0.5217,0.2642]
\end{aligned}
$$

In order to compare the relative optimization priorities of other first-level processes, the fuzzy comprehensive evaluation vector needs to be weighted averaged to obtain a numerical value that represents its FPOPN level, namely,

$$
C_{5}^{10}=B_{5}^{10} \cdot V^{T}=4.0057
$$

In the same way, the fuzzy comprehensive evaluation vectors and FPOPN levels of all other first-level processes can be obtained.

After the first-level fuzzy comprehensive evaluation of all first-level processes of the entire production process, the second-level fuzzy comprehensive evaluation can be carried out, and the FPOPN level of each second-level process can be obtained.

Taking the carburizing process design of the secondlevel process in the heat treatment stage as an example, the factor set is all the first-level processes involved in this second-level process, namely, $U=\left\{u_{5}^{5}, u_{5}^{6}, \ldots u_{5}^{11}\right\}$, the factor evaluation vector $V=[1,2,3,4,5]^{T}$, the evaluation matrix $R_{5-2}=\left[B_{5}^{5}, B_{5}^{6}, \ldots B_{5}^{11}\right]^{T}$, and the weight vector of the factor set is $W_{5-2}=[1 / 7,1 / 7, \ldots, 1 / 7]$. Then the comprehensive evaluation vector $B_{5-2}$ is as shown in (11).

$$
\begin{aligned}
B_{5-2} & =W_{5-2} R_{5-2} \\
& =[0.0982,0.1172,0.2107,0.3906,0.1833]
\end{aligned}
$$

The value of FPOPN level is as shown in (12).

$$
C_{5-2}=B_{5-2} \mathrm{~V}=3.4437
$$

In the same way, the fuzzy comprehensive evaluation vectors and FPOPN levels of all other second-level processes can be obtained.

4.4. The Analysis of Evaluation Results. After AHP-fuzzy comprehensive evaluation, the FPOPN level ranking of firstlevel fuzzy comprehensive evaluation is shown in Table 6. 
TABLE 6: The FPOPN level ranking of first-level fuzzy comprehensive evaluation.

\begin{tabular}{lcc}
\hline Serial number & First-level process & FPOPN level \\
\hline 1 & H-Diffusion time & 4.0663 \\
2 & H-Strong carburizing time & 4.0057 \\
3 & H-Carbon potential & 3.9895 \\
4 & H-Carburizing temperature & 3.9452 \\
5 & M-Grinding wheel speed & 3.9122 \\
6 & M-Feed rate & 3.9122 \\
7 & M-Type of grinding wheel & 3.7911 \\
8 & S-Hardenability bandwidth & 3.5166 \\
9 & M-Precision of grinding wheel installation & 3.5064 \\
10 & R-Tool slip velocity & 3.3904 \\
8 & $\ldots$ & $\ldots$ \\
\hline
\end{tabular}

TABLE 7: The FPOPN level ranking of second-level fuzzy comprehensive evaluation.

\begin{tabular}{lcc}
\hline Serial number & Second-level process & FPOPN level \\
\hline 1 & M-Grinding process design & 3.6250 \\
2 & H-Carburizing process design & 3.4437 \\
3 & S-Detecting hardenability & 3.4076 \\
4 & D-Tooth profile modification & 3.3435 \\
5 & D-Tooth shape modification & 3.3284 \\
6 & R-Shaving design & 3.1795 \\
7 & R-Hobbing design & 2.9972 \\
$\ldots$ & $\ldots$ & $\ldots$ \\
20 & S-Testing chemical composition & 2.6242 \\
\hline
\end{tabular}

Since 88 first-level processes are involved, only the top 10 processes are displayed.

According to the FPOPN level ranking of processes, the top four processes belong to the carburizing process design in the heat treatment stage, and the carburizing process determines the depth of carburizing layer and the surface hardness of gear teeth, which are decisive for the fatigue performance of the gear. The optimum carburizing layer depth corresponding to different gears does not have a certain standard value as a reference. Most gear factories only require the depth of the carburizing layer to be within a certain range. In addition, the processes affecting the depth of carburizing layer, such as carburizing temperature and strong carburizing time, are relatively easy to change, so it is convenient to carry out test research on gears with different process parameters, so their FPOPN levels are higher.

The processes ranked in the fifth, sixth, seventh, and ninth all belong to the grinding process design in the finishing stage. The grinding process determines the accuracy and roughness of the gear teeth. The high-precision gear is a necessary condition for high-end equipment to meet the extreme environmental requirements such as high speed, heavy load, impact, low noise, etc. Compared with some developed countries such as the United States and Germany, the processing accuracy of precision gears has generally reached grade 3-4, especially for some high-end measuring gears, which can even reach grade 2 , while the precision grade of this manufacturer's gears is generally between 5 and 7 , so their FPOPN levels are relatively high.

The above processes have something in common, that is, the process parameters are relatively easy to change and control, and it is difficult to determine the values of the parameters to maximize the performance of the gear, that is, whether the current process parameters are reasonable or not cannot be determined. However, the weight of changing difficulty of process parameters and rationality of the current process parameters is relatively high, so these processes' FPOPN levels are also relatively high. If the traditional FMECA method is used for analysis and ignoring the weight distribution among the factors, the detection difficulty factor with the lowest weight will be as important as the two factors mentioned above, which will lead to an unreasonable FPOPN level ranking. Therefore, it is more accurate and reasonable to evaluate the processes by the AHP-fuzzy comprehensive evaluation.

The FPOPN level ranking of the second-level fuzzy comprehensive evaluation is shown in Table 7 . Since 20 secondlevel processes are involved, only the top 7 processes are displayed.

It can be seen from the second-level fuzzy comprehensive evaluation that the carburizing process in heat treatment stage and the grinding process in finishing stage should be regarded as priority optimization processes. That is to say, if all the first-level processes of a certain second-level process 
TABLE 8: The basic size parameters of the gear.

\begin{tabular}{|c|c|c|c|c|c|c|c|}
\hline $\begin{array}{l}\text { Normal } \\
\text { modulus }\end{array}$ & $\begin{array}{c}\text { Tooth } \\
\text { number }\end{array}$ & $\begin{array}{l}\text { Pressure } \\
\text { angle }\end{array}$ & $\begin{array}{l}\text { Addendum } \\
\text { coefficient }\end{array}$ & $\begin{array}{l}\text { Clearance } \\
\text { coefficient }\end{array}$ & Helix angle & Tooth width & $\begin{array}{c}\text { Modification } \\
\text { coefficient }\end{array}$ \\
\hline $6 \mathrm{~mm}$ & 25 & $20^{\circ}$ & 1 & 0.25 & $0^{\circ}$ & $24 \mathrm{~mm}$ & 0 \\
\hline
\end{tabular}

Problem description: Introduce the current situation of the research object, as well as the problems to be solved or the goal of optimization.

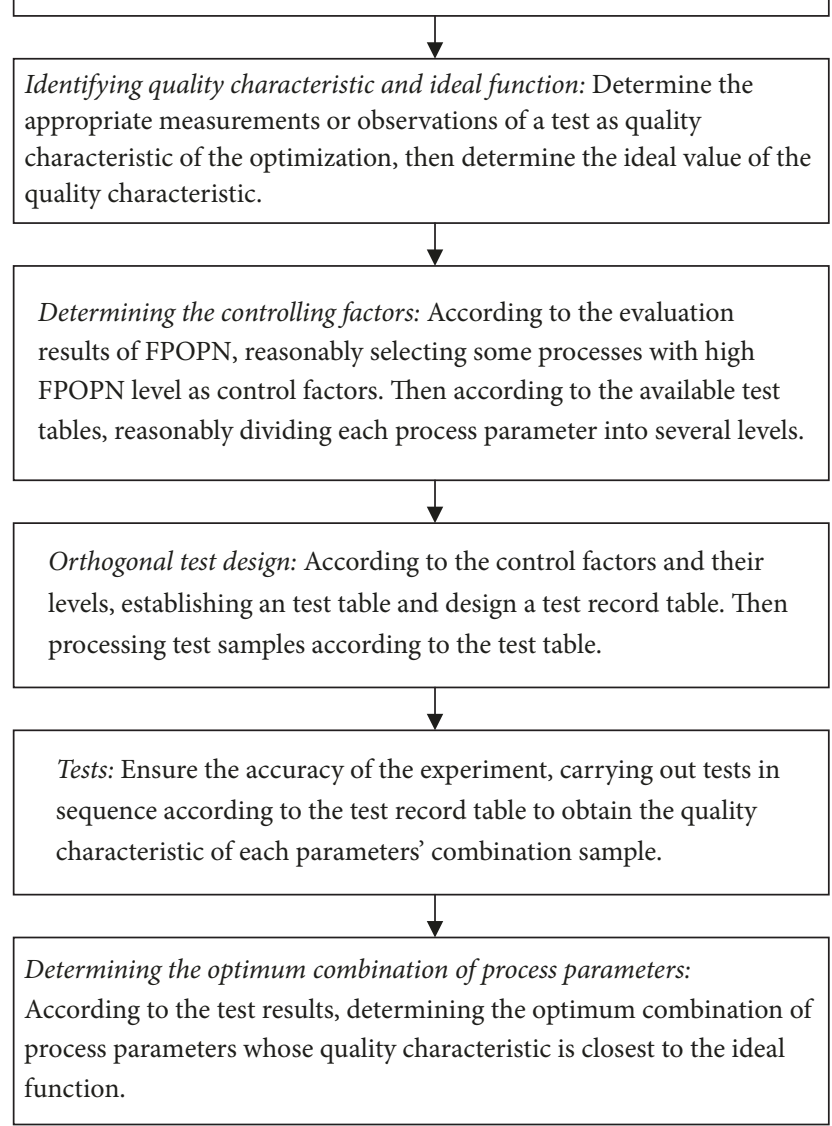

FIGURE 5: Taguchi method steps.

need to be improved and optimized, these two second-level processes should be preferentially selected.

\section{Process Optimization by Taguchi Method}

According to the evaluation results, several processes with the high FPOPN level need to be optimized and analyzed to obtain the optimal parameters' combination, and the Taguchi method is a powerful tool to do it. We can develop some specific steps for optimizing processes by Taguchi method, as shown in the Figure 5, and a detailed optimization process is taken as an example according to the steps.

5.1. Problem Description. This part mainly introduces the current situation of the research object, as well as the problems to be solved or the goal of optimization.

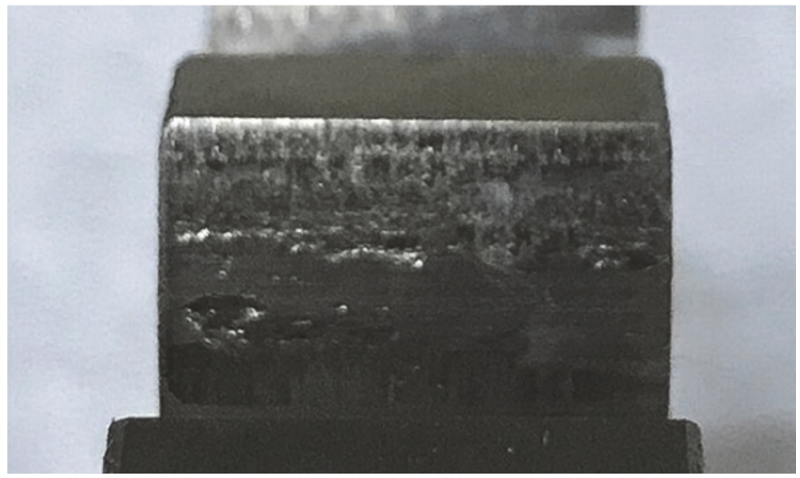

FIGURE 6: The pitting failure effect of one gear tooth surface.

In the example, the fatigue life of 20CrMnTi gear produced by a gear factory cannot meet the requirements of customers, it is required that the fatigue life of existing gears should be further extended or the fatigue limit of gears should be increased by optimizing the gear processes under specific working conditions. The basic size parameters of the gear are shown in Table 8.

\subsection{Identifying Quality Characteristic and Ideal Function.} This part mainly determines the appropriate measurement value or observation value of a test as a quality characteristic of the optimization, then determining the ideal value of the quality characteristic.

In the example, at the beginning, two quality characteristics are considered. One is the life of gears with different process parameters under the same working condition, and the other is the fatigue limit of gears with different process parameters that can be determined by the up and down method. Under the same contact stress, when comparing the life of gears with different process parameters, some gears will have very short life, while some other gears will have infinite life, that is to say, some other gears will have no life value because of the infinite life. For the fatigue limit, each gear with different process parameters has a corresponding fatigue limit value, so it is easier to analyze and calculate the test data by the Taguchi method. So the fatigue limit is chosen as the quality characteristic. As for the ideal function, the larger the fatigue limit, the better.

When the pitting area of one single tooth reaches $4 \%$ or the pitting area of the gear pair reaches $0.5 \%$ damage limit in a fatigue limit test, the tooth surface failure is determined, and the number of stress cycles is the failure life. If the number of cycles exceeds $1 e^{7}$, the contact fatigue life of the tooth surface is considered to be infinite life. Figure 6 shows the pitting failure effect of one gear tooth surface. 
TABLE 9: The original carburizing process parameters of the gear factory.

\begin{tabular}{lcccccc}
\hline $\begin{array}{l}\text { Carburizing } \\
\text { medium }\end{array}$ & $\begin{array}{c}\text { Carburizing } \\
\text { temperature }\end{array}$ & $\begin{array}{c}\text { Strong } \\
\text { carburizing } \\
\text { time }\end{array}$ & $\begin{array}{c}\text { Carburizing } \\
\text { carbon } \\
\text { potential }\end{array}$ & $\begin{array}{c}\text { Diffusion } \\
\text { temperature }\end{array}$ & $\begin{array}{c}\text { Diffusion } \\
\text { time }\end{array}$ & $\begin{array}{c}\text { Diffusion } \\
\text { carbon } \\
\text { potential }\end{array}$ \\
\hline Kerosene & $920^{\circ} \mathrm{C}$ & $2.5 \mathrm{~h}$ & $1 \%$ & $880^{\circ} \mathrm{C}$ & $1.5 \mathrm{~h}$ & $0.8 \%$ \\
\hline
\end{tabular}

TABLE 10: The levels of control factors.

\begin{tabular}{lccc}
\hline $\begin{array}{l}\text { Control } \\
\text { factors }\end{array}$ & $\begin{array}{c}\text { Strong } \\
\text { carburizing time }\end{array}$ & $\begin{array}{c}\text { Diffusion } \\
\text { time }\end{array}$ & $\begin{array}{c}\text { Grinding wheel } \\
\text { type }\end{array}$ \\
\hline Level 1 & $2.5 \mathrm{~h}$ & $1.0 \mathrm{~h}$ & $60 \#$ \\
Level 2 & $3.0 \mathrm{~h}$ & $1.5 \mathrm{~h}$ & $70 \#$ \\
Level 3 & $3.5 \mathrm{~h}$ & $2.0 \mathrm{~h}$ & $80 \#$ \\
\hline
\end{tabular}

TABLE 11: The test table.

\begin{tabular}{lccc}
\hline Serial number & Strong carburizing time & Diffusion time & Grinding wheel type \\
\hline 1 & $2.5 \mathrm{~h}$ & $1.0 \mathrm{~h}$ & $60 \#$ \\
2 & $2.5 \mathrm{~h}$ & $1.5 \mathrm{~h}$ & $70 \#$ \\
3 & $2.5 \mathrm{~h}$ & $2.0 \mathrm{~h}$ & $80 \#$ \\
4 & $3.0 \mathrm{~h}$ & $1.0 \mathrm{~h}$ & $70 \#$ \\
5 & $3.0 \mathrm{~h}$ & $1.5 \mathrm{~h}$ & $80 \#$ \\
6 & $3.0 \mathrm{~h}$ & $2.0 \mathrm{~h}$ & $60 \#$ \\
7 & $3.5 \mathrm{~h}$ & $1.0 \mathrm{~h}$ & $80 \#$ \\
8 & $3.5 \mathrm{~h}$ & $1.5 \mathrm{~h}$ & $60 \#$ \\
9 & $3.5 \mathrm{~h}$ & $2.0 \mathrm{~h}$ & $70 \#$ \\
\hline
\end{tabular}

5.3. Determining the Controlling Factors. According to the evaluation results of FPOPN, this part mainly reasonably selects some processes with high FPOPN level as control factors. Then according to the available test tables in the Minitab, reasonably divide each process parameter into several levels.

In the example, according to the results of the fuzzy comprehensive evaluation, and in order to minimize the amount of tests to save cost and time, only the diffusion time and strong carburizing time, which rank first and second in the first-level fuzzy comprehensive evaluation, are taken as the main optimization processes. At the same time, in order to simply verify the reasonableness of the results of the AHP-fuzzy comprehensive evaluation, the grinding wheel type ranked fifth is also taken as the optimization process.

Firstly, the controlling factors are the strong carburizing time and the diffusion time of carburizing process. Strong carburizing is for rapid infiltration, and diffusion is for a reasonable carbon concentration gradient so that there is a transition from high carbon content to low carbon. Table 9 shows the original carburizing process parameters of the gear factory. Under the condition of keeping other parameters unchanged, according to the expert's suggestion, the time of strong carburizing can be divided into three levels: $2.5 \mathrm{~h}$, $3 \mathrm{~h}$, and $3.5 \mathrm{~h}$, and because the ratio of strong carburizing to diffusion time is generally between $1: 1$ and 3:1, the diffusion time can be divided into $1 \mathrm{~h}, 1.5 \mathrm{~h}$, and $2 \mathrm{~h}$.

The second determined control factor is the type of grinding wheel. The type of grinding wheel affects the roughness level and accuracy level of the tooth surface; the smaller the particle size, the higher the roughness level and accuracy level. The original grinding wheel used in the gear factory is white corundum grinding wheel with particle size of 315250um; according to the experts' suggestion, the grinding wheel types are divided into three levels: 80 \# white corundum grinding wheel with particle size of 200-160um, 70\# white corundum grinding wheel with particle size of 250-200um, and $60 \#$ white corundum gear with particle size of 315250um.

The levels of control factors are shown in Table 10.

5.4. Test Design. According to the control factors and their levels, this part mainly establishes a test table and designs a test record table, then processing test samples according to the test table.

In the example, Minitab is used to generate the test table. There are two kinds of test tables about three factors and three levels. One has nine groups of tests, and the other is full factor level design, which has 27 groups of tests. Because the main purpose is to determine the optimum combination of process parameters and not to study the interaction between process parameters, nine groups of tests are selected to save cost and time. The test table is shown in Table 11.

According to Table 11, a total of nine groups of gears with different process parameters are manufactured by the gear factory for testing. Figure 7 shows the test gears.

5.5. Tests. This part mainly carries out the tests in sequence according to the test record table to obtain the quality 
TABLE 12: Calculation example of the up and down method.

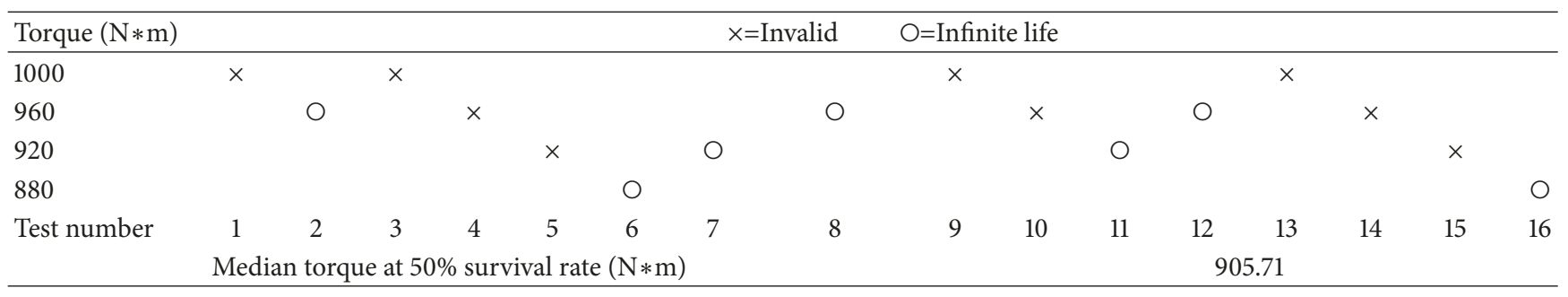

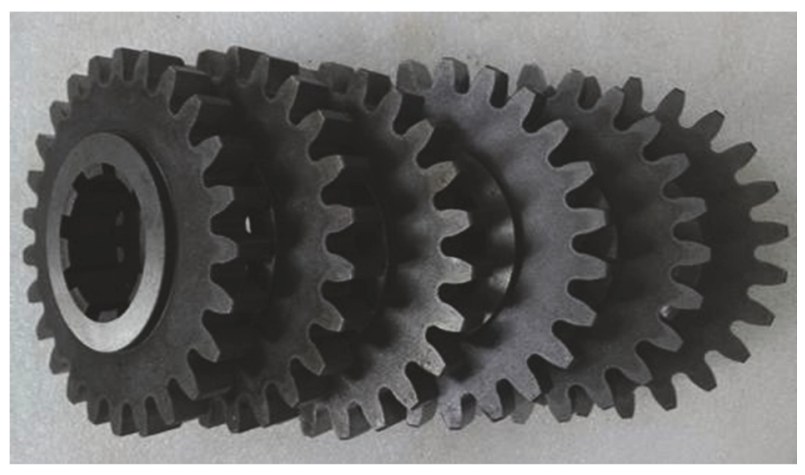

Figure 7: The test gears.

characteristic of each parameters' combination sample on the premise of ensuring the accuracy of the tests. In the example, choosing the mechanical closed gear test bench for gear tests, the overall structure of the mechanical closed gear test bench is shown in Figure 8. The torque applied by the loader causes a forced elastic deformation of the closed circuit to form a so-called "closed power", thereby loading the test gears. The power provided by the main motor is only consumed by friction and so on; that is to say, the tests of the high-power gearbox can be realized with a smaller driving power. In addition, the oil cooling system is used for heat dissipation in the gearbox, and the console is used to monitor the vibration state of the current gearbox and to count the cycles of the current gear fatigue test.

The objective of robust quality design is to determine the set level of control factors, so that the quality characteristic can achieve the desired function, and there is no excessive variation of the quality characteristic due to the changes of interference factors. Therefore, in order to ensure the ideal function of the quality characteristic, we should try our best to reduce the influence of interference factors before the tests.

Test machine debugging: in order to ensure the good running condition of gear test machine, the gear test machine is thoroughly inspected, the old gear shaft is replaced, some vulnerable bolts are replaced regularly, and the base of the test bench is fastened.

Oil cooling and lubrication system: for 24 hours of operation per day, the lubricant should be replaced every six months and ensure that the oil in the tank is sufficient to ensure good lubrication and heat dissipation of the gearbox.

Test operator: standardize the test operation, especially the operation of applying torque and assembling gears.
Tooth surface contact stress calculation: in order to ensure the accuracy of the calculation, ROMAX is used for modeling and simulation. By applying a certain amount of torque to the simulation tester, the tooth surface contact stress and the root bending stress during the gear operation can be obtained.

The determination of tooth surface fatigue failure: because the vibration change is small, it is difficult to judge whether the tooth surface is invalid by the vibration sensor signal. Therefore, the tooth surface observation is carried out to determine whether the tooth surface is invalid every four running hours.

After the preparation of the tests, the gear tests are carried out. Contact fatigue limits of different process gears are measured using the up and down method, which is the main method for determining the fatigue limit [30]. As shown in Table 12, taking the No. 1 process gear as an example, the torque value corresponding to the contact fatigue limit of the process gear is obtained by the up and down method (the specified life is $1 \mathrm{e}$, and the survival rate is $50 \%)$. Then the contact stress of the tooth surface corresponding to the torque value is obtained by the Romax simulation.

In the same way, the contact fatigue limits of the other 8 process gears can be obtained. The results are shown in Table 13.

5.6. Determining the Optimum Combination of Process Parameters. According to the test results, this part is mainly to determine the optimum combination of process parameters whose quality characteristic is closest to the ideal function through detailed discussion and analysis.

In this example, the Taguchi method is used to analyze the test results by Minitab. The Minitab response tables for SN ratios and means are shown in Table 14. Whether it is the SN ratios (Signal to Noise) response table or the mean response table, it can be seen that the diffusion time has the greatest influence on the tooth surface contact fatigue limit, followed by the strong carburizing time, and the influence of grinding wheel type is relatively small.

From the main effects plots for SN ratios and means in Figure 9, it can be seen that when the strong carburizing time changes from $2.5 \mathrm{~h}$ to $3 \mathrm{~h}$, it has a great influence on the fatigue limit; when changing from $3 \mathrm{~h}$ to $3.5 \mathrm{~h}$, the degree of influence is significantly reduced. The diffusion time, whether from $1 \mathrm{~h}$ to $1.5 \mathrm{~h}$ or from $1 \mathrm{~h}$ to $2 \mathrm{~h}$, has a great influence on the contact fatigue limit. For the type of grinding wheel, when the 60\# grinding wheel is changed to the 70\# grinding 


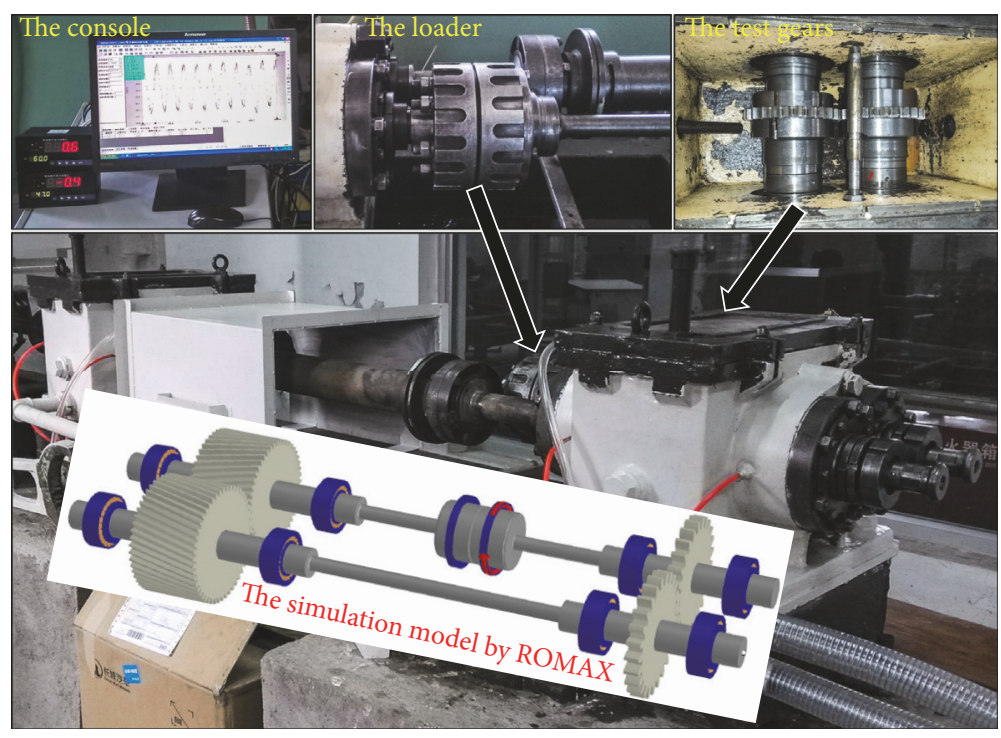

FIGURE 8: The overall structure of the mechanical closed gear test bench.

TABLE 13: The contact fatigue limits of different process gears.

\begin{tabular}{lcccc}
\hline Serial number & Strong carburizing time & Diffusion time & Grinding wheel type & Contact fatigue limit (MPa) \\
\hline 1 & $2.5 \mathrm{~h}$ & $1.0 \mathrm{~h}$ & $60 \#$ & 1382.01 \\
2 & $2.5 \mathrm{~h}$ & $1.5 \mathrm{~h}$ & $70 \#$ & 1752.82 \\
3 & $2.5 \mathrm{~h}$ & $2.0 \mathrm{~h}$ & $80 \#$ & 1914.70 \\
4 & $3.0 \mathrm{~h}$ & $1.0 \mathrm{~h}$ & $70 \#$ & 1601.37 \\
5 & $3.0 \mathrm{~h}$ & $1.5 \mathrm{~h}$ & $80 \#$ & 1816.50 \\
6 & $3.0 \mathrm{~h}$ & $2.0 \mathrm{~h}$ & $60 \#$ & 2014.93 \\
7 & $3.5 \mathrm{~h}$ & $1.0 \mathrm{~h}$ & $80 \#$ & 1677.17 \\
8 & $3.5 \mathrm{~h}$ & $1.5 \mathrm{~h}$ & $60 \#$ & 1829.26 \\
9 & $3.5 \mathrm{~h}$ & $2.0 \mathrm{~h}$ & $70 \#$ & 2032.73 \\
\hline
\end{tabular}

TABLE 14: The Minitab response tables for SN ratios and means.

(a) Response Table for Signal to Noise Ratios (Lager is Better)

\begin{tabular}{lccc}
\hline Level & Strong carburizing time $(\mathrm{h})$ & Diffusion time $(\mathrm{h})$ & Grinding wheel type \\
\hline 1 & 64.44 & 63.80 & 64.71 \\
2 & 65.12 & 65.10 & 65.04 \\
3 & 65.30 & 65.96 & 65.11 \\
Delta & 0.86 & 2.17 & 0.39 \\
Rank & 2 & 1 & 3 \\
\hline
\end{tabular}

(b) Response Table for Means

\begin{tabular}{lccc}
\hline Level & Strong carburizing time $(\mathrm{h})$ & Diffusion time $(\mathrm{h})$ & Grinding wheel type \\
\hline 1 & 1683 & 1554 & 1742 \\
2 & 1811 & 1800 & 1796 \\
3 & 1846 & 1987 & 1803 \\
Delta & 163 & 434 & 61 \\
Rank & 2 & 1 & 3 \\
\hline
\end{tabular}


TABLE 15: The partial prediction results of different process gears.

\begin{tabular}{lccc}
\hline Strong carburizing time $(\mathrm{h})$ & Diffusion time $(\mathrm{h})$ & Grinding wheel type & Contact fatigue limit $(\mathrm{MPa})$ \\
\hline 3.5 & 2 & $80 \#$ & 2076.30 \\
3 & 2 & $80 \#$ & 2040.85 \\
3.5 & 1.5 & $80 \#$ & 1888.37 \\
3 & 2 & $70 \#$ & 2033.70 \\
2.5 & 1.5 & $60 \#$ & 1644.44 \\
\hline
\end{tabular}
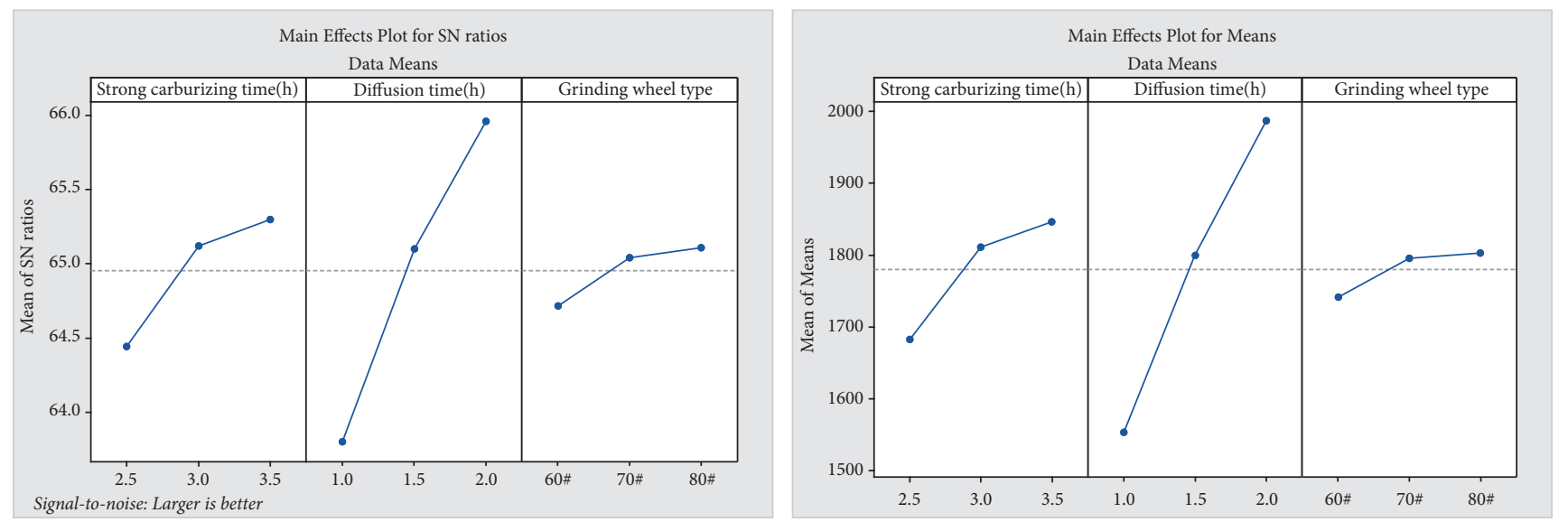

FIgURE 9: The main effects plots for SN ratios and means.

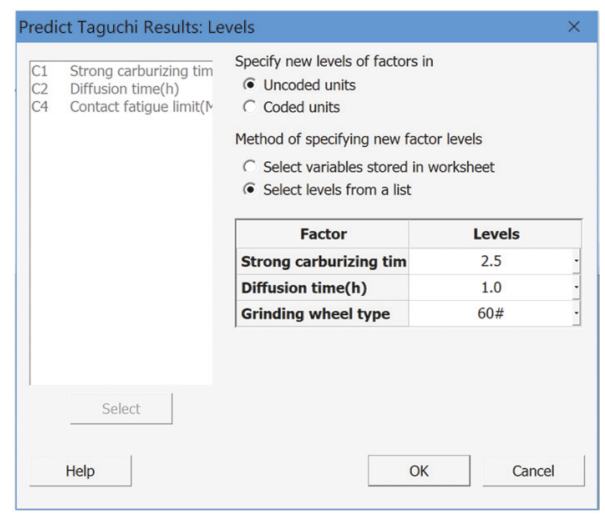

Figure 10: The Taguchi results are predicted by Minitab.

wheel, it has a small influence on the contact fatigue limit; and when the 70\# grinding wheel changes to $80 \#$, it has almost no effect on the contact fatigue limit. In conclusion, it is preliminarily determined that the optimum process parameters combination is $3.5 \mathrm{~h}$ for the strong carburizing time, $2 \mathrm{~h}$ for the diffusion time, and 80 \# for the grinding wheel type.

The contact fatigue limit of each process gear can also be predicted by the Minitab. As shown in Figure 10, the approximate contact fatigue limit corresponding to the process parameter combination can be obtained by inputting the level of each factor. The partial prediction results of different process gears are shown in the Table 15.
According to the gear tests and prediction results, there are two points that need special explanation. Firstly, when the infiltration time is $3.5 \mathrm{~h}$ and the diffusion time is $2 \mathrm{~h}$, the carburizing layer is too deep, and the core hardness is too high due to excessive carburization, which reduces the impact toughness of the teeth and may cause the gear root fracture phenomenon. In the tests, the phenomenon of root fracture of this process gear has occurred several times. Secondly, when the 70\# grinding wheel is changed to $80 \#$, it has almost no influence on the contact fatigue limit; considering the process cost, it is more reasonable to choose the 70 \# grinding wheel.

In conclusion, it is determined that the optimum process parameters combination is $3 \mathrm{~h}$ for the strong carburizing time, $2 \mathrm{~h}$ for the diffusion time, and 70\# for the grinding wheel type. Compared with the original process gears manufactured by the gear factory, the contact fatigue limit is increased from 1644.44 MPa to $2033.70 \mathrm{MPa}$, which is an increase of $23.67 \%$.

5.7. Analysis of Optimization Results. According to the above optimization results, in order to better demonstrate the effectiveness of the optimization method, the gear life prediction is performed on the optimal process parameter gear and the original process gear under different torque loads by the Romax simulation. The simulation model is shown in Figure 8; the model can predict the fatigue life of gears with different contact fatigue limits and torque loads. At the 1340 rpm of gear rotational speed, the prediction results are shown in Table 16, where the life unit is hour.

It can be seen from the prediction results, when the torque is the same, the fatigue life of optimal process gear is much 
TABLE 16: The fatigue life of gears with different contact fatigue limits and torque loads.

\begin{tabular}{lcc}
\hline Torque $(\mathrm{N} * \mathrm{~m})$ & The fatigue life of original process gear $(\mathrm{h})$ & The fatigue life of optimal process gear $(\mathrm{h})$ \\
\hline 800 & 2376.1 & $2.2 \mathrm{e} 6$ \\
900 & 507.2 & $3.3 \mathrm{e} 5$ \\
1000 & 310.5 & 61019.0 \\
1100 & 199.1 & 13222.7 \\
1200 & 132.6 & 3267.1 \\
1300 & 91.2 & 901.6 \\
\hline
\end{tabular}

TABLE 17: The costs of strong carburizing, diffusion time, and grinding wheels.

\begin{tabular}{lcccc}
\hline $\begin{array}{l}\text { The weight of } \\
\text { gear }(\mathrm{kg})\end{array}$ & $\begin{array}{c}\text { Strong carburizing } \\
\left(\mathrm{CNY} \cdot \mathrm{kg}^{-1} \cdot \mathrm{h}^{-1}\right)\end{array}$ & $\begin{array}{c}\text { Diffusion time } \\
\left(\mathrm{CNY} \cdot \mathrm{kg}^{-1} \cdot \mathrm{h}^{-1}\right)\end{array}$ & $\begin{array}{c}\text { 60\# grinding } \\
\text { wheel }(\mathrm{CNY})\end{array}$ & $\begin{array}{c}70 \# \text { grinding } \\
\text { wheel }(\mathrm{CNY})\end{array}$ \\
\hline 2.8 & 3.5 & 3 & 55 & 55 \\
\hline
\end{tabular}

longer than that of original gear, and when the fatigue life requirements are the same, the optimal process gear can load larger torque. That is to say, at the specified rotational speed, when the customer requires the gear to live for more than 2000 hours at a load torque of $800 \mathrm{Nm}$, then both gears can be used, and when the requirement of customer for torque is increased to $1200 \mathrm{Nm}$, the only choice is to use new process gears. The performance of optimal process gears also fully meets the requirements of the gear factory through the optimization method in this paper.

For the optimization cost of processes, the costs of strong carburizing, diffusion time, and grinding wheels are shown in Table 17 after consultation with the gear manufacturers. From Table 17, it can be calculated that the cost of each optimal process gear is 9.1 CNY more than that of the original process gear. However, due to the improved performance of optimal process gears, the price of gear can be raised from 280 CNY to $320 \mathrm{CNY}$; that is to say, each optimal process gear can earn 30.9 CNY more than the original one through the process optimization. It can be seen that, in POPN analysis method, the factor $\mathrm{C}$ with larger weight mainly considers the optimization cost, so the optimization method in this paper can effectively save the optimization cost, thus bringing higher benefits to the factory.

\section{Conclusion}

This paper has presented an optimization method for gear processes; through this method, the most worth optimized processes can be obtained and optimized, thus improving the reliability and supportability of gear products. And a detailed optimization example has been given from the beginning to end in accordance with the above methods, and compared with the original process gears, the optimized gears has a big increase in gear performance through the above optimization method. Throughout the full text, there are several conclusions that need to be summarized as follows:

(1) The POPN analysis method has been proposed in this paper with reference to the RPN analysis method of traditional FMECA. It not only considers the manufacturing cost and the rationality of the current process parameters, but also has detailed scoring standard for each influencing factor. This method is more suitable for the optimization priority analysis of gear manufacturing processes.

(2) In this paper, the combination of AHP-fuzzy comprehensive evaluation method and POPN analysis method has been used to overcome the shortcoming that the POPN analysis cannot distribute the weight of each influencing factor and the shortcoming that there are uncertainties in parameters involved in POPN, and finally the FPOPN level of each process parameter has been obtained. This method is more scientific, reasonable, and practical.

(3) In the example of optimization, according to the results of fuzzy comprehensive evaluation, some processes with high FPOPN level have been optimized based on the Taguchi method. Finally, the optimal combination of process parameters is obtained, and the gear performance of optimal process gear has a big increase by comparing with the original process gear. At the same time, according to optimization results, the rationality of the optimization method in this paper is also reflected to some extent.

(4) In the example of optimization, the FPOPN levels of a $20 \mathrm{CrMnTi}$ gear production processes have been analyzed and sorted, and some processes are optimized according to the sorting result by the Taguchi method, which provides reference and guidance for the gear factory to further optimize various processes. This method is also applicable to the analysis and optimization of processes of other types of gears, even if there are different process methods, equipment, and environments. At the same time, the whole analysis and optimization method mentioned above also has reference value for the formulation of processes improvement schemes for other products. 


\section{Data Availability}

The data used to support the findings of this study are available from the corresponding author upon request.

\section{Conflicts of Interest}

The authors declare that they have no conflicts of interest.

\section{Acknowledgments}

The authors are grateful for the financial support provided by the "Research on Fatigue Life-Cycle Reliability Theory and Method for Large and Complex Mechanical Structures" of Natural Science Foundation of China under Grant no. U1708255.

\section{References}

[1] Y. F. Li, S. Valla, and E. Zio, "Reliability assessment of generic geared wind turbines by GTST-MLD model and monte carlo simulation," Journal of Renewable Energy, vol. 83, pp. 222-233, 2015.

[2] IEC 60812, Analysis Techniques for System Reliability - Procedure for Failure Mode And Effects Analysis (FMEA), International Electrotechnical Commission, Geneva, Switzerland, 2006.

[3] M. Tweeddale, "Failure mode and effect analysis [FMEA] and failure mode and effect criticality analysis [FMECA] - managing risk and reliability of process plants - Appendix B[J]," Managing Risk \& Reliability of Process Plants, pp. 468-472, 2003.

[4] S. Carpitella, A. Certa, J. Izquierdo, and C. M. La Fata, "A combined multi-criteria approach to support FMECA analyses: a real-world case," Reliability Engineering \& System Safety, vol. 169, pp. 394-402, 2018.

[5] M. Catelani, L. Ciani, and M. Venzi, "Failure modes, mechanisms and effect analysis on temperature redundant sensor stage," Reliability Engineering \& System Safety, vol. 180, pp. 425433, 2018.

[6] H. C. Liu, L. Liu, and N. Liu, "Risk evaluation approaches in failure mode and effects analysis: a literature review," Expert Systems with Applications, vol. 40, no. 2, pp. 828-838, 2013.

[7] V. R. Renjith, M. Jose kalathil, P. H. Kumar, and D. Madhavan, "Fuzzy FMECA (failure mode effect and criticality analysis) of LNG storage facility," Journal of Loss Prevention in the Process Industries, Article ID S0950423017304205, 2018.

[8] A. Certa, M. Enea, G. M. Galante, and C. M. La Fata, "ELECTRE TRI-based approach to the failure modes classification on the basis of risk parameters: An alternative to the risk priority number," Computers \& Industrial Engineering, vol. 108, pp. 100110, 2017.

[9] M. Braglia and M. Bevilacqua, "Fuzzy modelling and analytical hierarchy processing as a means of quantifying risk levels associated with failure modes in production systems," Technology, Law and Insurance, vol. 5, no. 3-4, pp. 125-134, 2000.

[10] F. Zammori and R. Gabbrielli, "ANP/RPN: a multi criteria evaluation of the risk priority number," Quality and Reliability Engineering International, vol. 28, no. 1, pp. 85-104, 2012.

[11] M. Braglia, M. Frosolini, and R. Montanari, "Fuzzy TOPSIS approach for failure mode, effects and criticality analysis," Quality and Reliability Engineering International, vol. 19, no. 5, pp. 425-443, 2010.
[12] I. Emovon, R. A. Norman, A. J. Murphy, and K. Pazouki, "An integrated multicriteria decision making methodology using compromise solution methods for prioritising risk of marine machinery systems," Ocean Engineering, vol. 105, pp. 92-103, 2015.

[13] K. O. Kim and M. J. Zuo, "General model for the risk priority number in failure mode and effects analysis," Reliability Engineering \& System Safety, vol. 169, pp. 321-329, 2018.

[14] T. L. Saaty, Decision Making for Leaders: The Analytical Hierarchy Process for Decision in A Complex World, chapter 5, Lifetime Learning, Belmont, Calif, USA, 1982.

[15] J. Guo, Z. Lin, L. Zu, and J. Chen, "Failure modes and effects analysis for $\mathrm{CO} 2$ transmission pipelines using a hesitant fuzzy VIKOR method," Soft Computing, pp. 1-18, 2018.

[16] R. Fattahi and M. Khalilzadeh, "Risk evaluation using a novel hybrid method based on FMEA, extended MULTIMOORA, and AHP methods under fuzzy environment," Safety Science, vol. 102, pp. 290-300, 2018.

[17] D. V. Petrović, M. Tanasijević, V. Milić, N. Lilić, S. Stojadinović, and I. Svrkota, "Risk assessment model of mining equipment failure based on fuzzy logic," Expert Systems with Applications, vol. 41, no. 18, pp. 8157-8164, 2014.

[18] A. John, D. Paraskevadakis, A. Bury, Z. Yang, R. Riahi, and J. Wang, "An integrated fuzzy risk assessment for seaport operations," Safety Science, vol. 68, pp. 180-194, 2014.

[19] N. Chanamool and T. Naenna, "Fuzzy FMEA application to improve decision-making process in an emergency department," Applied Soft Computing, vol. 43, pp. 441-453, 2016.

[20] Y. Ozdemir, M. Gul, and E. Celik, "Assessment of occupational hazards and associated risks in fuzzy environment: A case study of a university chemical laboratory," Human and Ecological Risk Assessment, vol. 23, no. 4, pp. 895-924, 2017.

[21] R. Ahmad, S. Kamaruddin, I. A. Azid, and I. P. Almanar, "Failure analysis of machinery component by considering external factors and multiple failure modes - A case study in the processing industry," Engineering Failure Analysis, vol. 25, pp. 182-192, 2012.

[22] M. Wang and N. Dongxiao, "Research on project postevaluation of wind power based on improved ANP and fuzzy comprehensive evaluation model of trapezoid subordinate function improved by interval number," Journal of Renewable Energy, vol. 132, pp. 255-265, 2019.

[23] N. A. Wessiani and S. O. Sarwoko, "Risk analysis of poultry feed production using fuzzy FMEA," Procedia Manufacturing, vol. 4, pp. 270-281, 2015.

[24] B.-S. Yu and Y.-Y. Liu, "Improvement in phase purity and yield of hydrothermally synthesized smectite using Taguchi method," Applied Clay Science, vol. 161, pp. 103-109, 2018.

[25] A. Pander, K. Ishimoto, A. Hatta, and H. Furuta, "Significant decrease in the reflectance of thin CNT forest films tuned by the Taguchi method," Vacuum, vol. 154, pp. 285-295, 2018.

[26] B. Sun, J. Xiao, Z. Li et al., "An analysis of soil detachment capacity under freeze-thaw conditions using the Taguchi method," Catena, vol. 162, pp. 100-107, 2018.

[27] M. Firouzi, A. Niknejad, S. Ziaee, and M. R. Hematiyan, "Optimization of $\mathrm{H}$-shaped thin-walled energy absorber by Taguchi method and a new theoretical estimation for its energy absorption," Thin-Walled Structures, vol. 131, pp. 33-44, 2018.

[28] D. Ji, Z. Wei, S. Mazzoni et al., "Thermoelectric generation for waste heat recovery: Application of a system level design optimization approach via Taguchi method," Energy Conversion and Management, vol. 172, pp. 507-516, 2018. 
[29] T. L. Saaty and L. G. Vargas, Models, Methods, Concepts \& Applications of the Analytic Hierarchy Process, 2012.

[30] ISO 12107-200, "Metallic Materials-Fatigue Testing-Statistical planning and analysis of data," 2003. 


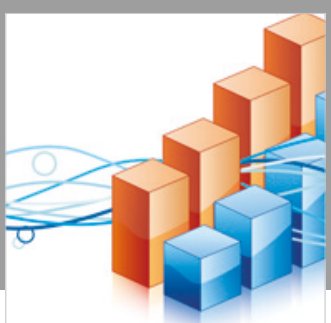

Advances in

Operations Research

\section{-n-m}
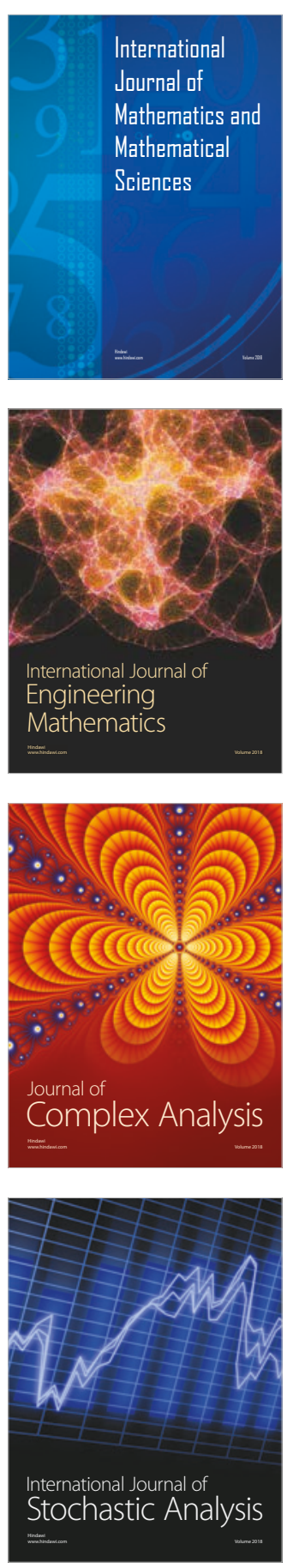
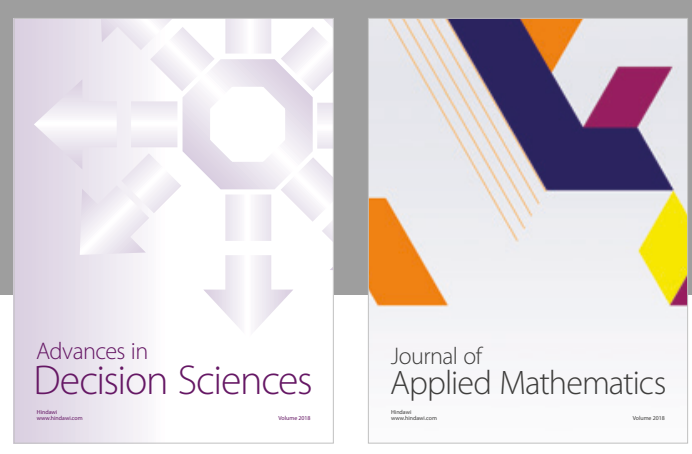

Journal of

Applied Mathematics
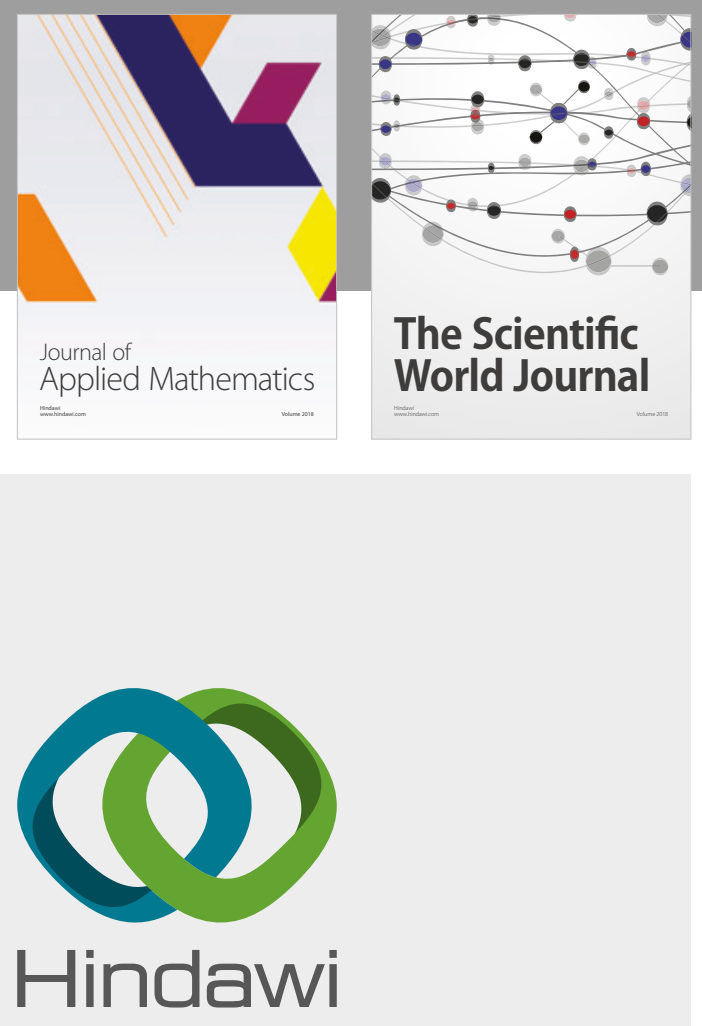

Submit your manuscripts at

www.hindawi.com

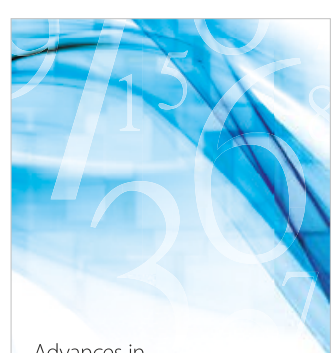

Advances in
Numerical Analysis
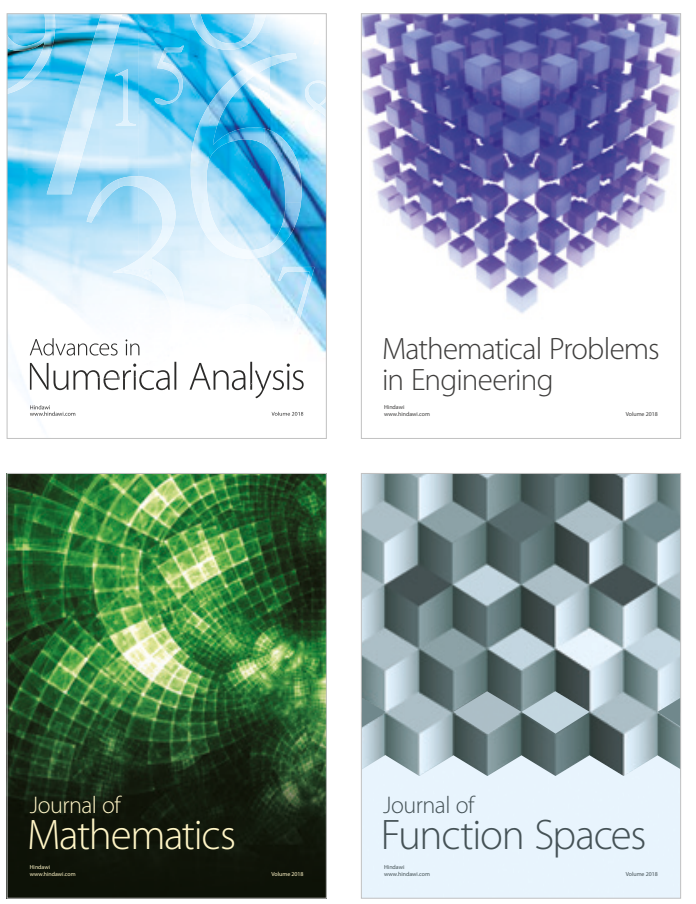

Mathematical Problems in Engineering

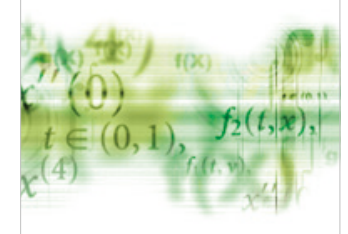

International Journal of

Differential Equations

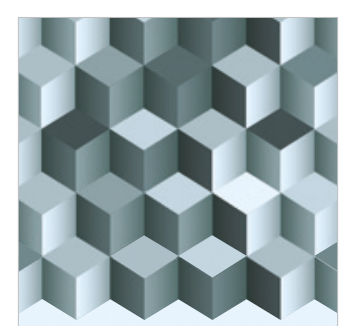

Journal of

Function Spaces

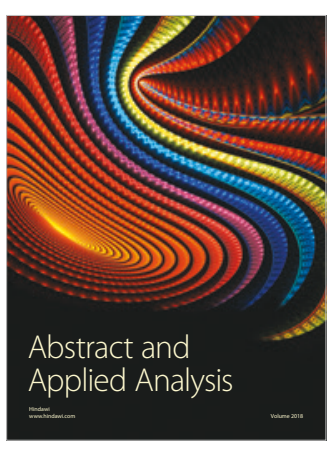

The Scientific

World Journal

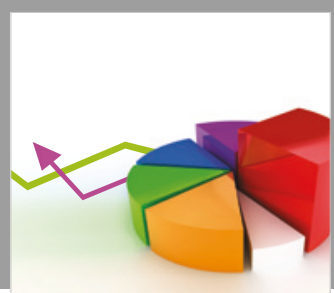

Journal of

Probability and Statistics
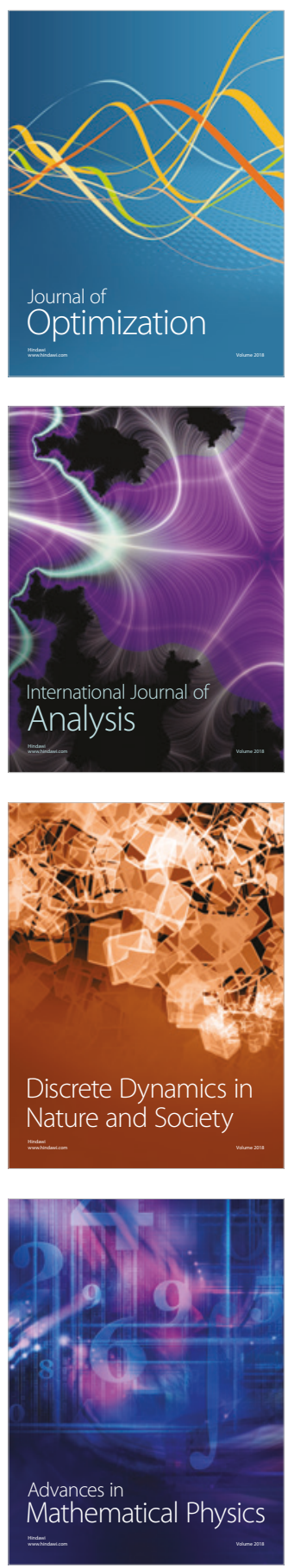